\title{
PERIFERIA: A PRODUÇÃO DO ESPAÇO E REPRESENTAÇÕES SOCIAIS NO/DO BAIRRO RESTINGA - PORTO ALEGRE/RS
}

\author{
Nola Patrícia Gamalho ${ }^{1}$, Álvaro Luiz Heidrich ${ }^{2}$
}

\section{Resumo}

A fragmentação do solo urbano produz um mosaico, confinando segmentos sociais a frações espaciais distintas. Paralelamente, desenvolvem-se imaginários na construção das representações do espaço (LEFEBVRE, 2000). De um lado o espaço estereotipado, de outro o espaço de representação, solidificado a partir das trajetórias individuais para a aquisição da casa própria. Adquirir um lote na periferia é a possibilidade de ascender à condição de proprietário para grande parte da população, criando fortes vínculos do sujeito com o espaço que o abriga. Essas reflexões partem do estudo de caso do bairro Restinga, localizado na zona sul de Porto Alegre (RS). É no embate entre a produção do espaço e a produção das representações do espaço e do espaço de representação que partem as discussões aqui propostas.

Palavras-chave: periferia, espaço, representações, Restinga.

\begin{abstract}
Urban soil fragmentation produces a mosaic, boarding social segments on distinct special fractions. At the same time, imaginaries are developed at the construction of space representation (LEFEBVRE, 2000). On one hand, there is the stereotyped space; on the other hand, there is the representation space, which is consolidated from individual ways to the acquisition of the own house. Getting a lot at the outskirts is the possibility of ascending to the owner condition to most of the population. This condition creates strong links between the individual and the space where he lives in. These reflections start at the case study of Restinga neighborhood, at the South area of Porto Alegre (RS, Brazil). The discussions proposed here start from the confrontation between the production of space and the space of representation.
\end{abstract} Key-words: outskirts, space, representations, Restinga

\footnotetext{
${ }^{1}$ Mestranda do Programa de Pós-Graduação em Geografia da Universidade Federal do Rio Grande do Sul. ${ }^{2}$ Professor, Doutor, do Programa de Pós- Graduação em Geografia da Universidade Federal do Rio Grande do Sul.
} 


\section{Pontos de partida}

O objetivo de diálogo desse texto está centrado na produção do espaço da periferia e suas representações, contextualizando-as dentro de suas conceituações, em um exercício de diálogo com senso comum e o campo científico, assim como, no âmbito de sua produção vinculada ao espaço vivido, percebido e concebido (LEFEBVRE, 2000). Corresponde a um exercício de compreensão das metamorfoses do espaço e da construção de seus significados.

O termo periferia está presente no cotidiano da sociedade, aparece na mídia ${ }^{3}$, avança no senso comum, é interpretado nos corpos e incorpora valores. É simultaneamente abstração, exercício teórico, político e ideológico e, materialidade, pois compõe o espaço vivido de determinado segmento social. Como objeto de estudo, abordamos a produção do espaço no Bairro Restinga- Porto Alegre- RS, conhecida e reconhecida a partir de sua condição de bairro periférico.

A cidade é fragmentada em bairros que refletem muito mais do que o parcelamento administrativo do solo urbano e, nesse sentido, os sujeitos são referenciados de acordo com sua localização nesse mosaico, compondo a hierarquização do espaço. O acesso ao solo ocorre de forma desigual, já que o mesmo participa da lógica da mercadoria, estando na relação em que o valor de troca predomina sobre o valor de uso e como conseqüência tem-se a espacialização da divisão social e técnica do espaço, pois segundo Carlos (2001):

(...) há uma lógica que tende a se impor como 'ordem estabelecida' que define o modo como a cidade vai-se reproduzindo a partir da reprodução, realizada pela ação dos promotores imobiliários, das estratégias do sistema financeiro e da gestão política, às vezes de modo conflitante (...) mas em todos os casos orientando e reorganizando o processo de reprodução espacial por meio da realização da divisão socioespacial do trabalho, da hierarquização dos lugares e da fragmentação dos espaços vendidos e comprados no mercado. A ação do Estado - por intermédio do poder local - ao intervir no processo de produção da cidade reforça a hierarquia de lugares, criando novas centralidades e expulsando para a periferia os antigos habitantes, criando um espaço de dominação. (CARLOS, 2001, p. 15):

A periferia é um produto da lógica de parcelamento desigual, o que torna imprescindível a discussão acerca de sua forma atual, pois as configurações espaciais não são estáticas no tempo, mas intensamente mutáveis. As distâncias, os deslocamentos não são os mesmos para os diferentes sujeitos, nesse sentido é preciso refletir além da dicotomia centro-

\footnotetext{
${ }^{3}$ A periferia está sempre presente nas novelas, no núcleo "popular" das mesmas e em programas, como o da Rede Globo, "Central da Periferia”, que é realizado em diferentes periferias do Brasil e do mundo, tendo ocorrido também no Bairro Restinga - Porto Alegre. Da mesma forma“ A Diarista”, outro programa da mesma emissora, constrói uma caricatura do morador da periferia, abordado a partir de sua inserção na divisão do trabalho.
} 
periferia enquanto representação estática do espaço geográfico. Essas reflexões são realizadas a partir das tensões na produção do espaço e das representações sociais do bairro Restinga.

Para a realização dessa leitura acerca da periferia foi utilizada a metodologia da entrevista qualitativa proposta por Michelat (1980), em que é realizado um diálogo cuja motivação é a história de vida do morador. O papel do entrevistador é incentivar e direcionar as explanações de acordo com os interesses da pesquisa. A partir da história de vida surgem os elementos da produção do espaço.

Conforme esta metodologia, a amostra não é qualitativa, mas diversificada, a fim de abranger a amplitude dos universos de significação. A seleção de informantes ocorre na forma de uma teia, de um emaranhado de relações e contatos. Parte-se de um diálogo continuado com José Carlos (morador da Restinga Nova), o primeiro nó dessa teia, indicando o contato com outros nós em outras unidades. A proposta pretende tornar mais amplo o universo de significações pesquisado.

\section{A periferia na produção do espaço e das representações}

A especulação imobiliária associada ao poder público constantemente atua na reconfiguração espacial e na produção de novas espacialidades. A construção do bairro Restinga, ao final da década de 1960, corresponde a esse processo de transformação e criação de espacialidades. A Restinga se originou a partir da remoção de segmentos sociais que já vinham expulsos do campo pelo processo de êxodo rural e são novamente re-assentados dentro da cidade. Corresponde ao processo de "higienização" das áreas de interesse estratégico à especulação imobiliária, culminando com a remoção de famílias pobres de vilas próximas ao centro, como a Ilhota, Theodora, Marítimos, entre outras . Esse processo constitui-se na interferência associada do Estado e da especulação imobiliária na destruição e re-construção destas áreas, alterando sua forma, função e estrutura. É, segundo Carlos (2001, p. 17) “(...) a contradição entre as estratégias do Estado (visando a reprodução do capital e a produção de um espaço dominado) e os usos do espaço (objetivando a reprodução da vida) (...)".

Em função da distância do centro, de aproximadamente 26 quilômetros, ter permanecido por um longo período com precário sistema de transporte público, infra-estrutura urbana e saneamento básico, o bairro foi reconhecido como periferia. Contudo, cabe problematizar o conceito, para que seu uso acadêmico não se confunda com o senso comum. 
Não só a produção do espaço é dotada de intenção, mas também a produção do pensamento acerca desse espaço. Carlos (2006, p. 12) argumenta que: “(...) não raro, a cidade vem sendo pensada ora como quadro físico, ora como meio ambiente urbano (nessa dimensão, 'naturalizada'), e em ambos os casos, ocultando o conteúdo da prática socioespacial que lhe dá a forma e o conteúdo". Reduzir a periferia a sua condição de distância física e sua condição social aos aspectos de pobreza corresponde a uma forma de ocultar toda a pluralidade das práticas sociais que produzem esse espaço.

A periferia aparece, freqüentemente, vinculada à questão da distância do centro e associada ao segmento populacional pobre, de onde surgem as reflexões quanto ao espaço de exclusão sócio-territorial. Essa perspectiva se faz presente na representação do morador da periferia a partir da leitura enquanto lugar de produção de estratégias de vida particulares do espaço, na formação de modos de vida singulares, em um reconhecimento de que a fragmentação espacial é de viés social. Nessa linha, Durham (1986) afirma que:

\footnotetext{
A população pobre está em toda a parte nas grandes cidades. Habita cortiços e casas de cômodos, apropria-se das zonas deterioradas e subsiste como enclaves nos interstícios dos bairros mais ricos. Mas há um lugar onde se concentra, um espaço que lhe é próprio e onde se constitui a expressão mais clara de seu modo de vida. É a chamada periferia. A 'periferia' é formada pelos bairros mais distantes, mais pobres, menos servidos por transporte e serviços públicos.(DURHAM, 1986, p.86)
}

Embora não restrinja a população pobre a uma periferia vinculada à distância, destaca o termo como social, vinculando-o aos modos de vida desenvolvidos na uniformidade e segregação compartilhados por determinada população, em que a partir da ordem próxima (LEFEBVRE, 2006) potencializa-se a constituição de redes de solidariedade.

Rolnik e Bonduki (1982) destacam a periferia a partir da aquisição da moradia popular, vinculada à reprodução da força de trabalho da população de baixa renda. São processos que ocorrem a partir do acesso diferencial à propriedade privada. Destacam a indiscriminada utilização do termo, em uma perspectiva geográfica, a partir da distância do centro e, uma perspectiva sociológica, na configuração de espaços de reprodução da força de trabalho. Nesse sentido, procuram formular uma definição mais precisa, conceituando a periferia como "parcelas do território da cidade que têm baixa renda diferencial" (ROLNIK E BONDUKI, 1982, p.147). A renda diferencial corresponde às diferenças de localização, condições físicas, e aos investimentos aplicados sobre o terreno.

Os autores destacam esse critério de definição, que vincula os sujeitos de acordo com a possibilidade de aquisição de moradia, salientando que a distância não é definidora pois, próximo aos centros, existem zonas de baixa renda diferencial e, em áreas distantes, zonas de 
alta renda diferencial. Exemplo disso são os condomínios fechados que proliferam nas áreas mais distantes, mas com outros valores incorporados.

A cidade configura-se a partir da proliferação de novas centralidades e da constituição de enclaves fortificados de segmentos tanto da classe média-baixa, quanto da média-alta. Paviani (1996, p. 183) destaca que: "Processos recentes têm apresentado periferias 'nobres', no linguajar dos empreendedores imobiliários, isto é, 'condomínios fechados', 'villages', ou ‘ cidades jardins', ocupados pela classe média ou mesmo pela classe mais abastada (...)”.

Caminhamos para o entendimento do termo periferia a partir de seu viés social, de que a estratificação social é produtora da fragmentação do espaço e que, embora o senso comum ainda assuma o termo periferia enquanto local de vivência da população pobre, o mesmo pode corresponder a feições elitistas, como os condomínios fechados. Desta forma, a periferia é aqui abordada não se referindo à distância física, mas também à social, em uma hierarquia de espaços e sujeitos. São processos alicerçados em aspectos ideológicos na construção da distância social, pois conforme Bourdieu (2007) :

\footnotetext{
Pode-se assim representar o mundo social em forma de um espaço (a várias dimensões) construído na base de princípios de diferenciação ou de distribuição constituídos pelo conjunto das propriedades que actuam no universo social considerado, quer dizer, apropriadas a conferir, ao detentor delas, força ou poder nesse universo. Os agentes e grupos de agentes são assim definidos pelas suas posições relativas neste espaço. Cada um deles está acantonado numa posição ou numa uma classe precisa de posições vizinhas (...) (BOURDIEU, 2007, p.1334):.
}

O recorte espacial é também um recorte de classe que, através das representações do espaço, intensifica as distinções sociais. A produção de alteridades e as representações sociais tornam-se uma estratégia do capital. Os estilos de vida são uma tática em que um grupo socialmente localizável se marca e demarca, agregando, intencionalmente, valores positivos ou negativos aos espaços.

\section{Restinga: quando a produção do espaço perpassa o acesso à moradia}

A produção do espaço na Restinga ocorreu sob o lema "Remover para promover", quando o poder público reassentou a população de vilas (FIG. 1) que se localizavam próximo ao centro. Observando a FIGURA 1, percebe-se a rarefação das vias de Porto Alegre na zona Sul, o que corrobora a característica de menor acesso e sua posição espacial distante do centro. Contudo, na mesma região, proliferam condomínios fechados, que incorporam alta renda diferencial. 
FIGURA 1 - Localização do Bairro Restinga e as vilas de origem

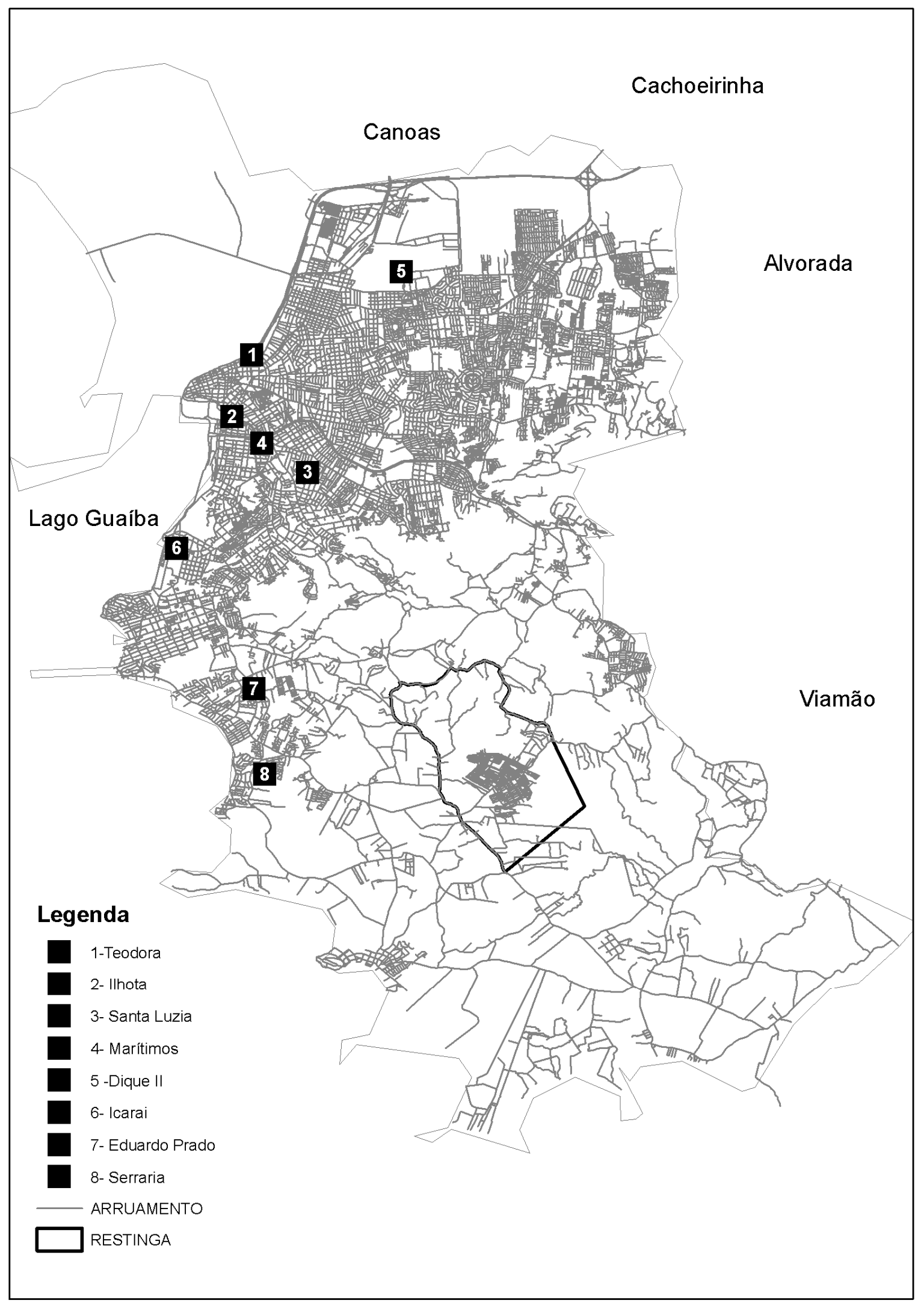

FONTE: Heidrich ,2000. Alterado por Nola Patrícia Gamalho. 
Entre tais condomínios destacam-se dois, ambos pela Avenida Edgar Pires de Castro, caminho para chegar ao bairro Restinga. Há o "Lagos de Nova Ipanema" e o "Moradas do Sul", ${ }^{\prime}$, que não são remetidos à distância enquanto entrave, mas enquanto solução, na busca por qualidade de vida, lugares calmos e arborizados. Nesse sentido a renda diferencial reflete a necessidade de enquadramento ideológico, como apontam os fragmentos da propaganda dos empreendimentos:

\begin{abstract}
A preservação ambiental é outro ponto fundamental. O residencial Lagos de Nova Ipanema terá 40 mil metros quadrados de áreas verdes integradas ao projeto urbanístico. Todo o complexo foi concebido em sintonia com os mais altos padrões de desenvolvimento sustentável. (sitie Nova Ipanema)

Este é o lugar da sua vida

O loteamento Moradas do Sul está localizado numa região de grande valorização da Zona Sul de Porto Alegre, na Avenida Edgar Pires de Castro, n 2300, próximo à rótula da Juca Batista. O empreendimento se destaca pela sua completa e moderna infra-estrutura de lazer. (sitie Bolognesi)
\end{abstract}

Estes empreendimentos estão distantes do centro, na zona sul. Contudo perpassam diferentes representações e nesse sentido a distância incorpora valores positivos tanto ao espaço quanto aos sujeitos que adquirem status através da aquisição da casa. Nesse sentido as representações acabam servindo para ocultar a produção da diferenciação socioespacial. Agregam-se valores de saúde, tranqüilidade, felicidade. É a produção ideológica dos espaços de felicidade, o lugar do sujeito no mundo, desde que ele esteja apto a consumir essa mercadoria.

O acesso à moradia é a constituição da distância social, o que determina que um dos sujeitos habita na periferia e o outro na Zona Sul, e isso representa a estratificação simbólica da estratificação social. O direito à moradia é reduzido ao direito de consumo. Contudo, o sonho da casa própria não é apenas uma meta de consumo, mas, para a população dita "periferizada", é a estabilidade em um percurso de degradação entre aluguéis, favores e despejos.

Identificamos no bairro Restinga (FIG. 2) algumas trajetórias de aquisição da casa própria: re-assentamento realizado pelo poder público (Restinga Velha, Barro Vermelho); aquisição de moradia popular em projetos habitacionais (Restinga Nova), loteamentos clandestinos (Vale do Salso, Bita), loteamentos ( Chácara do Banco, Flor da Restinga); ocupações (Rocinha, Invasão do Asun ${ }^{6}$ ). Aqui o termo periferia serve para designar duas

\footnotetext{
${ }^{4}$ Casas não padronizadas, cujos preços variam de R\$155.000,00 a 700.000,00.

${ }^{5}$ Pequenas casas com 2 ou 3 dormitórios, o preço é a partir de $\mathrm{R} \$ 60.750,00$.

${ }^{6}$ A ocupação tem popularmente esse nome por estar localizada atrás do supermercado Asun.
} 
características: distância física e distância social. Nesse contexto, a própria Restinga reproduz a fragmentação da cidade, como pode ser observado na seguinte fala:

Entrevistado 1: a Restinga é uma periferia que dentro dela tem várias periferias ainda. Tem mais periferias dentro dessa periferia. A Restinga é longe né? Tem lugares na Restinga que são bem na periferia da Restinga. Tem aqueles lugares na Velha, de canto.

Entrevistado 2: a Restinga é a periferia de Porto Alegre, mas tem a periferia da Restinga que é enorme.(...), a Restinga, tu tira uma base, a Restinga é a periferia de Porto Alegre, se for tratar a periferia como a zona pobre da cidade a zona ..., tu calcula o que é a periferia da Restinga. (Moradores da Restinga Nova, entrevista realizada em 20/03/2008).

A Restinga, enquanto periferia, é a possibilidade para os periferizados adquirirem a moradia. São formas diferentes de aquisição. Contudo, são as possibilidades desse segmento de adquirir uma pseudo estabilidade, pois de um lado é a fuga de aluguéis e opressões, de outro é uma redução da cidadania à condição de proprietário. E nesse percurso a história de vida se confunde com a história de aquisição da casa própria, agregando valores positivos ao espaço em que o indivíduo encontra esse abrigo. Nesse sentido, tem-se a tensão entre a representação que é construída acerca da periferia e, conseqüentemente, do periferizado, e a representação construída no espaço, o que Lefebvre (2000) denomina de representação do espaço, para o primeiro caso e, espaço de representação para o segundo. A representação da periferia é ancorada no imaginário da precariedade, carência de infra-estrutura e violência.

\section{FIGURA 2 - Localização Unidades do bairro Restinga}
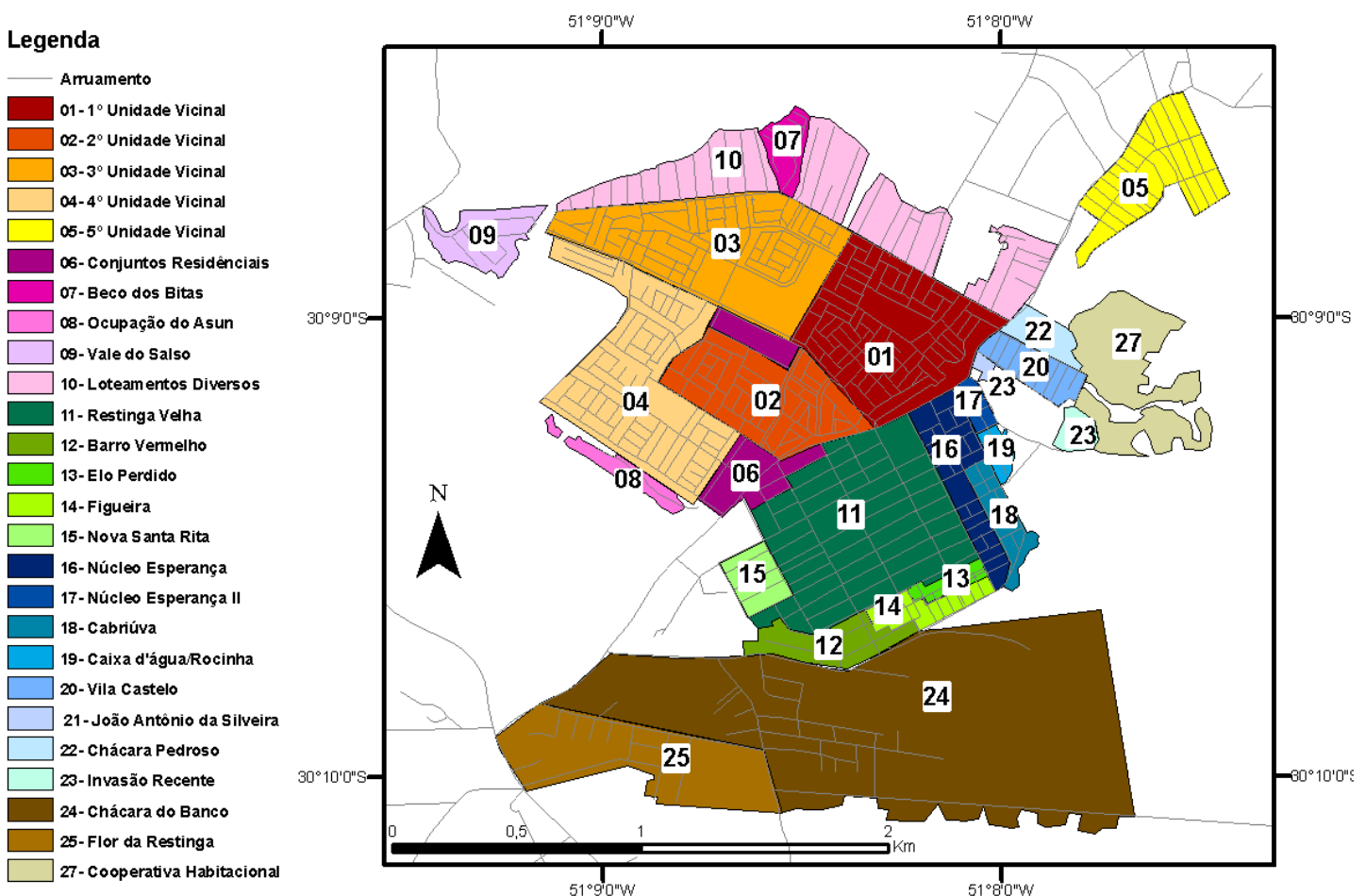

Fonte: Nola Patrícia Gamalho. 
As possibilidades de aquisição da moradia ocultam o processo de segregação socioespacial ao mesmo tempo em que revelam que viver e habitar a periferia é a arte da invenção, desde as estratégias de aquisição da moradia, até o ideário e práticas de melhoria, freqüentemente percebido como "progresso". O percurso de aquisição da casa própria é marcado por relatos permeados por muita opressão, o que amarra os laços com o lugar de acolhimento, que adquire nuances de liberdade: do aluguel, do favor e da precariedade, como pode ser observado no relato seguinte:

\begin{abstract}
Entrevistada: não, eu saí de lá e fui morar com um irmão meu no Menino Deus, depois que eu me separei dele. Depois do Menino Deus ele chegou pra mim e disse: Eu te dei pra morar por uns tempo e não pra morar pra vida inteira. Aí eu fiquei ofendida com aquilo ali, fazia três anos e meio que eu morava ali e fui embora. Aí eu disse pra uma amiga: Não tem uma casa pra me emprestar pra eu morar até... Eu não quero mais ficar aqui. E era lá no Teresópolis. Ela disse, tem uma peça lá, podia ter botado tu lá, recém foram os caseiros pra lá. Eu te dou. Aí nós fomos pra lá, depois eu vim para a Costa Gama e fizemos duas peças no terreno do meu irmão, ali na casa dele. Aí eu não queria mais ficar ali, daí eu soube que invadiram aqui. Eu queria, "mas tu não mora lá porque é muito tiro, muita bala, muita coisa" (simulando fala do irmão para ela). Aí eu fui né, aí um dia morreu o meu sobrinho e ele disse pra minha irmã: mãe ajuda a Tia Emi. Ele morreu aqui na Restinga, morreu num acidente de moto. Mas antes dele morrer ele disse: mãe ajuda a tia Emi. Aí eu não tinha mais onde morar, eu não tinha mais casa, não tinha mais emprego, não tinha mais nada. Eu tinha umas máquinas que eu emprestei pra minha irmã, daí ela me, acho que tinha malha junto, tinha moldes que fazia pra ganhar um dinheirinho. Aí eu emprestei minhas máquinas pra ela e ela me deu 1000 reais pra mim dá entrada nessa casinha que era uma casinha bem pequenina, daí eu vim pra cá.(Moradora da Vila Bita, entrevista em 28/03/200/).
\end{abstract}

O relato acima é um demonstrativo da tensão entre as representações do espaço que aparece na fala do irmão da entrevistada e o espaço de representação que surge a partir da posse da casa, do lugar em que a entrevistada encontra o seu "porto seguro". A vila Bita, periferia do bairro Restinga surgiu por ocupação e loteamento irregular, apresentando intensa precariedade, pois não havia infra-estrutura pública e as moradias eram improvisadas . São elementos que chocam, ancorando a representação do espaço em aspectos de insalubridade. Contudo, é o início da caminhada em busca do progresso que se estende da casa para a rua. Tem-se um percurso de luta pela casa própria, histórias, embates que contribuem para a consolidação dos laços espaciais, como pode ser observado nesse relato:

Entrevistado: não, agora tem tudo de todo mundo, esse valo aqui e sai lá na entrada da Restinga, ele vem lá do Mapa, do Pinheiro, então tudo o que tem no caminho vem ali. Aí o meu irmão e esse cara, nós pegamos o terreno e começamos a limpar aqui, nós limpamos daqui até a casa da dona Emi e foi com enxada e facão e aí precisava dormir aqui pra cuidar o material...

Nola: e garantir o lugar...

Entrevistado: e garantir o lugar, então eu fazia assim, eu dormia aqui até a ameaça de pontada, quando eu ficava com ameaça de pontada eu voltava a dormir lá na casa 
da minha mãe, aí eu me recuperava da ameaça de pontada e voltava aqui, voltava a ter ameaça de pontada e vamos pra lá.

Nola: valeu a pena?

Entrevistado: valeu, valeu a pena, hoje tenho uma casa que é minha, coisa que muito amigo meu não tem, não conseguiu, tem uma coisa que é minha, um cantinho pra cuidar dos filhos, porque mesmo estando junto com os parentes é difícil, agente nunca pode, de repente ser o enérgico que agente queria ser pra cortar aquilo na hora certa, né? Então é minha casa, pode não ser das melhores, das mais maravilhosas do mundo, mas é onde agente consegue viver e sobreviver por enquanto, né? (Morador da Vila Bita, entrevista em 16/06/2008).

A aquisição da casa própria como luta se repete em inúmeras narrativas, corroborando a construção do espaço de representação em um processo de valorização da propriedade, do lugar e da casa. Essa trajetória não encerra ao adquirir o imóvel, o progresso vem junto com a melhoria da casa. É uma paisagem (FIG. 3 ) comum na periferia as casas sem reboco ou em construção e essa situação constitui-se, por um lado, nas representações do espaço enquanto precariedade, porém na construção do espaço de representação é o progresso, é a substituição da maloca, da casinha de madeira, de compensado (FIG. 4), por uma de tijolo.

\section{FIGURA 3 - Casas inacabadas -}

\section{Restinga Velha.}

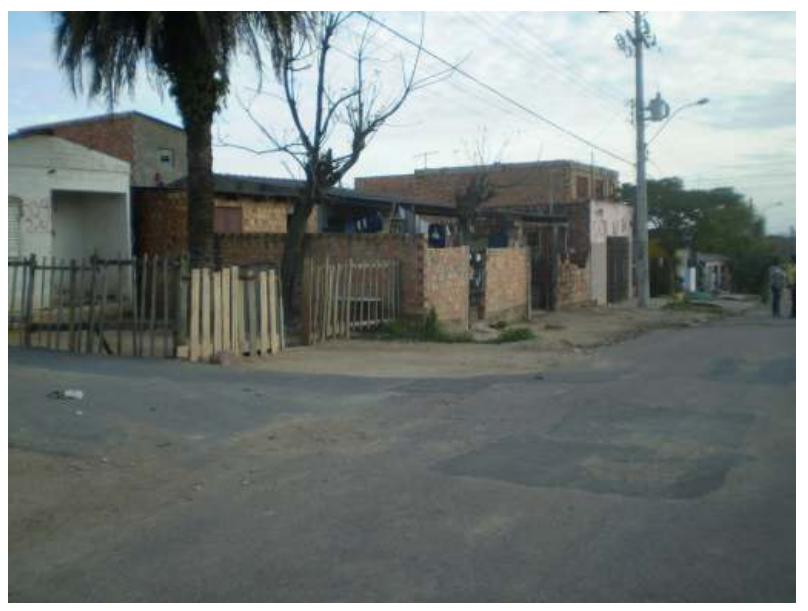

Fonte: Nola Gamalho, agosto de 2008.

\section{FIGURA 4 - Casa de diversos materiais} - Elo Perdido

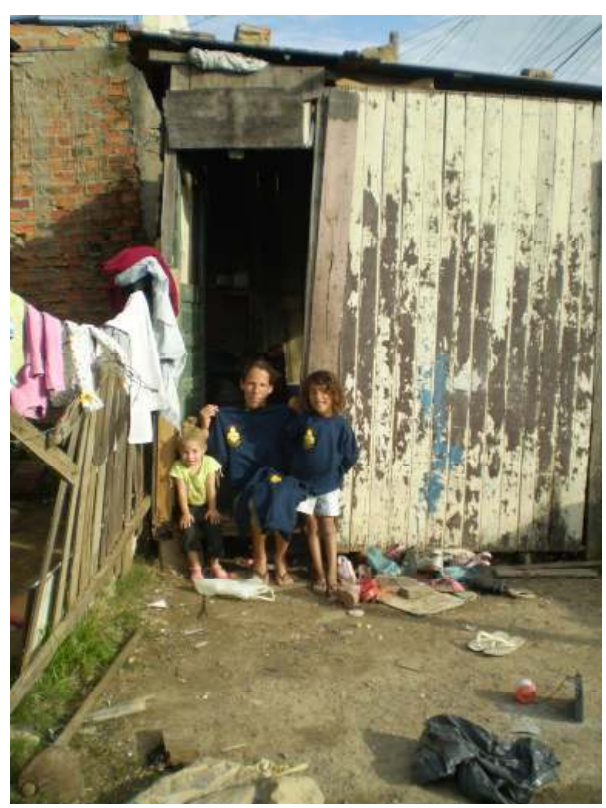

Fonte: Nola Gamalho, agosto de 2008.

Nesse processo de construção predomina a mão de obra familiar, de forma gradual e constante, já que corresponde a um importante gasto familiar, disputando com outras prioridades. Segundo Rolnik e Bonduki (1982, p. 129): “(...) ao produzir sozinho a sua casa, o trabalhador cria um valor de uso, apropriado totalmente por ele, e que é potencialmente uma mercadoria, pois pode ser comercializado a qualquer momento". A casa é simultaneamente 
poupança e abrigo e construí-la vai além de uma estratégia de economia, pois agrega o valor simbólico de ter sido construída com as próprias mãos. O relato seguinte aponta a necessidade de autoconstrução e da casa enquanto prioridade no orçamento familiar.

\begin{abstract}
Entrevistado: aí o falecido meu tio comprou material e agente foi arrumando devagarzinho. Pedia uma mão pra um,uma mão pra outro, que tem primo pedreiro e tem eu de servente, então fizemos. Pra não pagar um profissional, um profissional vai cobrar, pra te levantar uma parede dessas aí ele vai te cobrar $\mathrm{R} \$ 40,00$, uma parede dessas aí, num dia. Aí vai levar 5 ou 6 dias. Quanto vai? É um montão de dinheiro. (Figueira, entrevista em 15/08/2008)

Entrevistada: (...) Natal passado eu não dei nada pra eles, porque eu sento e converso com eles: olha filhos é isso,isso e isso, quer que mãe faz? A mãe faz, mas vai faltar pra isso e isso. Se a mãe arrumar o piso vocês vão ver que a casa vai estar bonitinha, vai estar rebocada, mas não vão ganhar presente. Esse vai ser o presente de vocês, vocês querem? Não querem a mãe da o presente e a casa fica assim. Aí eles optaram que eu arrumasse a casa, que agente entrasse no final do ano dentro de uma casa decente.(Castelo, entrevista em:19/04/2008)
\end{abstract}

A identificação de progresso com a melhoria da residência também ocorre em áreas de assentamento em casas da prefeitura. $\mathrm{O}$ fragmento abaixo corresponde à Vila Castelo, local de assentamento de inscritos na política de produção habitacional do Departamento Municipal de Habitação (DEMHAB). A luta pelo recebimento da casa própria também corresponde a trajetórias de opressão, precariedades e humilhações, como segue abaixo:

Entrevistado 1: o que eu posso te dizer Nola, é que agente é rico agora. Eu falei pra ela: olha eu sou rico, perto do que agente passou....

Entrevistado 2: ah, eu também, mas eu morei sabe, numa peça, eu morava numa peça menor que essa aqui. Aqui tem uma peça nesse terreno do lado, não sei se vocês repararam, eu morei numa peça que só cabia a cama, o fogão e só. Não cabia uma cadeira, nada. Eu e a Aline. Aqui na Restinga também, aí depois que eu mudei nessa peça, sabe, aqui depois, tu chegou a ver,na frente de onde era a escolinha. Quando eu saí da escolinha que eu passei, eu acho pro outro lado da rua. A dona Temi, te lembra da dona Temi? O velho Pedro que vivia doente da asma.

Entrevistado 1: sim, do outro lado ali pro campinho.

Entrevistado 2: não, na calçada da falecida chinesa, Oldair. Ali que eu morei. Quando eu sai dali eu fui pra uma peça enorme de grande, uma peça só, só que ida daqui .... e aí o que eu tinha? Eu só tinha aquela cama de solteiro com a Aline, um armarinho de botar as roupas, e o fogãozinho de duas bocas. Aquilo naquela baita casa, na outra era pequeno pra muita coisa e a outra era grande, mas eu não tinha nada. E assim eu vivia a vida.(Moradora da Vila Castelo, entrevista em 19/04/2008)

Em algumas situações, como no caso das invasões, a aquisição da moradia apresentase em um quadro de extrema precariedade, podendo formar um laço permanente ou temporário com o espaço. $\mathrm{Na}$ invasão do $\mathrm{Asun}^{1}$, os laços são temporários, formando uma

\footnotetext{
${ }^{1}$ Ocupação localizada atrás do supermercado Asun.
} 
espacialidade de transição para outra situação, ou seja, por aquisição, outra invasão ou assentamento em outra área regularizada, como os assentamentos na Castelo e na Chácara do Banco. Esses espaços de moradia temporária agregam valores negativos aos seus moradores, pois a perspectiva de melhoria ou de acesso à dignidade é associada à aquisição da casa própria em outro lugar.

Entrevistado: não, eu fui morar de aluguel na Restinga Velha, morei de aluguel, quando terminou o meu dinheiro do aluguel eu construí uma casinha nas Invasão. Morei nas invasão do Unidão, (...)Aí a $\operatorname{UDESCA}^{2}$ veio na minha casa para eu participar. Chegando eles na minha casa: Mas o Oldair mora aqui nas Invasão? E eu tendo que pular pelos lodos pra entrar na minha casa e eu mestre-sala da Imperadores do Samba, uma escola grande. Aí um deles disse assim: Oldair, me empresta o banheiro. E eu não tinha banheiro. Eu tinha um quadradinho que tinha uma cortininha que eu colocava um balde pras pessoas fazerem xixi, eu não tinha banheiro. Aí eu disse que eu não vou ficar aqui, eu vou lutar. Fiquei 8 meses ali e com o dinheiro da Imperadores eu comprei meu lá na quinta Unidade. (Morador da Restinga Nova $-5^{\circ}$ Unidade, entrevista em $02 / 04 / 2008$ ).

Segundo Rolnik e Bonduki (1982, p. 138): “O trabalhador, ao optar pela casa própria, não visa apenas eliminar o gasto mensal com a habitação, mas objetiva também a formação de um patrimônio(...)". Esse é certamente um ponto importante na aquisição da moradia, mas não o principal, pois a precarização de parte desse segmento social os excluí da capacidade de optar, não há escolha. É nesse contexto de precariedade que proliferam múltiplos processos de compra e venda marcados por estratégias que tangenciam as formas de comércio capitalista.

Entrevistada: Já estava na minha mão. E aí o que acontece, eu botei a chave dependurada com o voto, o sangue de Jesus tem o poder, boto o olho por terra e a inveja também e me dá a vitória. E o que aconteceu, em uma semana eu liguei pra ela: escuta aqui, eu tenho um som três em um, daqueles antigos e uma televisão de 14 polegadas. (...) tudo funcionando, só antigo. Ta to indo aí. Olhou... Ta me dá mais R\$ 100,00 . Não, se eu vou te dar os R\$ 100,00, eu to mentindo. Não tenho, mas olha aqui óh, arregacei o balcão, tinha um pacote de farinha dentro do balcão e uma lata de óleo. Ta me dá esse som e a televisão e fica com a casa. (moradora da Invasão do Asun - aguardando assentamento na Chácara do Banco, entrevista em 05/04/2008).

Entrevistada: primeiro eu morei lá no aluguel que nem ele tava falando, daí quando ele foi eu queria também ir, né? Porque o aluguel consome muito agente, né? O aluguel era R\$120,00, e a mulher queria aumentar mais ? E o banheiro era separado, era caro, não valia a pena. Agente ta pagando uma coisa que não é da gente. Daí ele aí, o meu ex-marido que é o pai das crianças: "Aí, porque tu só inventa moda e não sei o que?" Não, eu quero ir lá pras Invasão. Aí fomos lá pras Invasão, aí o cara tinha invadido uma casa lá, uma pré-moldada muito bonitinha. Daí eu fui lá, falei com ele, o amigo do meu marido também foi lá e falou com ele. Aí ele disse assim: não, se vocês querem eu vendo pra vocês. Aí eu bah, negócio fechado, eu quero. Só não tinha banheiro, aí nós compremos por $\mathrm{R} \$ 700,00$, e fiquemos uns anos lá. (ex-

\footnotetext{
${ }^{2}$ União dos destaques do carnaval de Porto Alegre.
} 
moradora da Invasão do Asun- foi assentada na Vila Castelo, entrevista em 19/04/2008).

Estas situações envolvem diferentes segmentos sociais, todos marcados pelo processo de segregação espacial imposto e camuflado pela fragmentação hierárquica do solo urbano. Nas invasões, predomina um segmento que faz parte apenas parcialmente desse mercado de consumo, desenvolvendo estratégias de habitação e de relações sociais particulares, onde o que aparece no senso comum como caótico (precariedade das casas e da escassa infraestrutura, intensa religiosidade, brigas de vizinhança) compõe na realidade formas criativas de sobrevivência dentro das possibilidades de existência que esse segmento possui.

\section{Conclusão}

Os processos de produção e reprodução da forma urbana não são estáticos, estão em constante movimento alterando formas, funções, representações. Nesse sentido, ao abordar o termo periferia, é necessário esclarecer quais os parâmetros de definição, já que a mesma é altamente mutável. Proliferam condomínios fechados em áreas distantes, nas bordas da cidade, assim como permanecem enclaves de pobreza próximos às áreas centrais. A perspectiva aqui abordada vai de encontro ao pensamento acerca da periferia a partir das condições de acesso ao solo urbano dos segmentos sociais de menor renda.

Constitui-se em uma exclusão camuflada pelo acesso ao solo urbano como mercadoria e os sujeitos são reduzidos à condição de consumidores. Habitar adquire status diferentes: de um lado é uma distinção social na produção de bairros simbolicamente valorizados, por outro lado é o abrigo, o lugar em que os segmentos mais fragilizados encontram seu refúgio. Nesse sentido é que se deve estar atento ao papel das representações do espaço e ao espaço de representação. O primeiro é a sociedade vendo a periferia, o segundo é a periferia se vendo. Ambos são construções que acionam elementos pertinentes aos objetivos de sua construção.

As possibilidades de existência na periferia adquirem aspectos de criatividade contrapondo com a dimensão do consumo, que visa um fim acabado e esteticamente asséptico. Embora permeado por representações que degradam o espaço, os laços socioespaciais são muito consolidados, confrontando o espaço de representação (da casa, da estabilidade) como a representação do espaço (ancorada na precariedade, na violência e no tráfico). É a partir da trajetória de degradação e da aquisição da casa própria que o individuo vai significar o espaço que o acolhe. É a partir da produção da casa que se tem a produção do espaço, da rua e da vizinhança. 
Outro aspecto relevante corresponde à produção de representações homogêneas da periferia. Contudo, percebe-se que a mesma possui suas singularidades e espacialidades diversas. Compreende-se que desde a forma de aquisição da moradia, até as estratégias de transformação da mesma, se dão de múltiplas formas.

O elemento comum da produção dessas espacialidades é o próprio estigma, decorrente da representação do espaço, e o espaço enquanto lugar de reprodução da vida, vivido com o corpo, sensações e emoções. É através da trajetória da casa própria que esses sentimentos são produzidos, agregando valores ao espaço.

\section{Referências Bibliográficas}

BOLOGNESI - Empreendimentos Moradas do Sul. Disponível em $<$ www.bolognesi.com.br/site/?interface=empreendimento $>$ Acesso em 15 ago.2008.

BONDUKI, Raquel; BONDUKI, Nabil. Periferia da grande São Paulo. Reprodução do espaço como expediente de reprodução da força de trabalho. In: MARICATO, Ermínia (org.). A produção capitalista da casa (e da cidade) no Brasil industrial. 2. ed. São Paulo, 1982, p.177-154.

BOURDIEU, Pierre. Gosto de Classe e estilo de vida. In: Pierre Bourdieu: sociologia. 2ed., São Paulo: Ática, 1983.

O poder simbólico. 4ed. Rio de Janeiro: Bertrand Brasil, 2007.

CARLOS, Ana Fani Alessandrini. Espaço-tempo na metrópole: a fragmentação da vida cotidiana. São Paulo: Contexto, 2001.

Uma leitura sobre a cidade, Cidades: Revista Científica. Presidente Prudente, V.1,n.1,

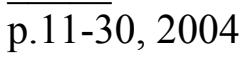

DAMIANI,Amélia Luisa. A propósito do espaço e do urbano: algumas hipóteses. , Cidades: Revista Científica. Presidente Prudente, V.1, n.1, p.79-95, 2004.

DURHAM, Eunice Ribeiro. A sociedade vista da periferia. Revista brasileira de ciências sociais da Associação Nacional de Pós-graduação, V.1, n.1, p.84-99, 1986.

HEIDRICH, Rosanne Lipp João. Projeto e realidade na consolidação de uma área urbana : Bairro Restinga - Porto Alegre/RS. 2000. 189 f. Dissertação (Mestrado em Planejamento Urbano e Regional) - Faculdade de Arquitetura, Universidade Federal do Rio Grande do Sul, Porto Alegre, 2000.

LAGOS DE NOVA IPANEMA. Disponível em:

<www.novaipanema.net/site/empreendimentos/ > Acesso em: 15 ago.2008.

LEFEBVRE, Henri. La producion de l'espace. 4. ed. Paris: Anthropos, 2000. 
A revolução urbana. Belo Horizonte: Ed. UFMG, 1999.

O direito à cidade. 4.ed. São Paulo: Centauro, 2006.

MARICATO, Ermínia. Autoconstrução, a arquitetura do possível. In: MARICATO, Ermínia (org.). A produção capitalista da casa (e da cidade) no Brasil industrial. 2. ed. São Paulo, 1982, p.71-94.

MICHELAT, Guy. Sobre a utilização de entrevista não- diretiva em sociologia. In.: THIOLLENT, Michel. Crítica metodológica, investigação social e enquête operária. São Paulo: Editora Polis LTDA, 1980. p. 191-212.

MOSCOVICI, Serge. Representações sociais: investigações em psicologia social. Petrópolis, RJ: Vozes, 2003.

PAVIANI, A. A lógica da periferização em áreas metropolitanas. In: SANTOS et al. (Org.). Território: globalização e fragmentação. São Paulo: HUCITEC, 1996. p.182-90.

TELLES, Vera da Silva. Pobreza e cidadania. São Paulo: Editora 34, 2001. 